\title{
Beneficial effects of sevoflurane and desflu- rane against myocardial reperfusion injury after cardioplegic arrest
}

Benedikt Preckel MD,
Volker Thämer MD, ${ }^{*}$
Wolfgang Schlack MD DEAA

Purpose: To determine whether sevoflurane or desflurane offer additional protective effects against myocardial reperfusion injury after protecting the heart against the ischemic injury by cardioplegic arrest.

Methods: Isolated rat hearts in a Langendorff-preparation $(n=9)$ were arrested by infusion of HTK cardioplegic solution and subjected to $30 \mathrm{~min}$ global ischemia followed by $60 \mathrm{~min}$ reperfusion (controls). An additional 18 hearts were subjected to the same protocol, and sevoflurane $(n=9)$ or desflurane $(n=9)$ was added to the perfusion medium during the first 30 min of reperfusion in a concentration corresponding to $1.5 \mathrm{MAC}$ in rats. Left ventricular (LV) developed pressure and creatine kinase $(\mathrm{CK})$ release were determined as indices of myocardial performance and cellular injury, respectively.

Results: The LV developed pressure recovered to $46 \pm 7 \%$ of baseline in controls. Functional recovery during reperfusion was improved by inhalational anesthetics to $67 \pm 3 \%$ (sevoflurane, $P<0.05$ ) and $61 \pm 5 \%$ of baseline (desflurane, $P<0.05$ ), respectively. Peak CK release during early reperfusion was reduced from $52 \pm 11$ $\mathrm{U} \cdot \mathrm{min}^{-1} \cdot \mathrm{g}^{-1}$ in controls to $34 \pm 7$ and $26 \pm 7 \mathrm{U} \cdot \mathrm{min}^{-1} \cdot \mathrm{g}^{-1}$ in sevoflurane and desflurane treated hearts, respectively. The CK release during the first 30 min of reperfusion was reduced from $312 \pm 41 \mathrm{U} \cdot \mathrm{g}^{-1}$ in control hearts to $195 \pm 40$ and $206 \pm 37 \mathrm{U} \cdot \mathrm{g}^{-1}$ in sevoflurane and desflurane treated hearts.

Conclusion: After ischemic protection by cardioplegia, sevoflurane and desflurane given during the early reperfusion period offer additional protection against myocardial reperfusion injury.

Objectif : Déterminer si le sévoflurane ou le desflurane offrent des effets protecteurs supplémentaires contre une lésion de reperfusion myocardique après qu'on a protégé le coeur contre l'ischémie par un arrêt cardioplégique.

Méthode : Des coeurs de rats isolés dans une préparation de Langendorff $(n=9)$ ont été arrêtés par la perfusion d'une solution cardioplégique HTK et soumis pendant $30 \mathrm{~min}$ à une ischémie globale suivie de $60 \mathrm{~min}$ de reperfusion (témoins). D'autres coeurs (18) ont été soumis au même protocole, mais du sévoflurane $(n=9)$ ou du desflurane $(n=9)$ a été ajouté au liquide de perfusion pendant les 30 premières min de la reperfusion selon une concentration correspondant à I,5 CAM chez les rats. La pression développée dans le ventricule gauche (VG) et la libération de créatine-kinase (CK) ont été déterminées en qualité d'indices de performance myocardique et de lésion cellulaire, respectivement.

Résultats : La pression du VG est revenue à $46 \pm 7 \%$ des valeurs de base dans les coeurs témoins. La récupération fonctionnelle pendant la reperfusion a été améliorée par les anesthésiques d'inhalation à $67 \pm 3 \%$ (sévoflurane, $P<0,05$ ) et à $61 \pm 5 \%$ des données de base (desflurane, $P<0,05$ ), respectivement. La libération maximale de CK au début de la reperfusion a été réduite de $52 \pm 11 \mathrm{U} \cdot \mathrm{min}^{-1} \cdot \mathrm{g}^{-1}$, chez les témoins, à $34 \pm 7$ et à $26 \pm 7 \mathrm{U} \cdot \mathrm{min}^{-1} \cdot \mathrm{g}^{-1}$ dans les coeurs traités avec le sévoflurane et le desflurane, respectivement. La libération de CK pendant les 30 premières min de la reperfusion a été réduite de $312 \pm 4 \mathrm{IU} \cdot \mathrm{g}^{-1}$, chez les témoins, à 195 \pm 40 et à $206 \pm 37 \mathrm{U} \cdot \mathrm{g}^{-1}$ dans les coeurs traités au sévoflurane et au desflurane.

Conclusion : Le sévoflurane et le desflurane administrés pendant le début d'une reperfusion, après qu'on a assuré une protection ischémique par cardioplégie, offrent une protection supplémentaire contre les lésions myocardiques de reperfusion.

From the Institut für Klinische Anaesthesiologie and Physiologisches Institut I, ${ }^{*}$ Heinrich-Heine-Universität, Postfach 101007 , D-40001 Düsseldorf, Germany.

Address correspondence to: Dr. W. Schlack, Phone: 49-211-81-12651; Fax: 49-211-81-12655; E-mail: wolfgang@herzkreis.uni-duesseldorf.de Accepted for publication July 11,1999 
I $\mathrm{N}$ our current understanding of ischemia-reperfusion injury, reperfusion injury is clearly distinguished from the ischemic injury itself. Reperfusion injury is the additional postischemic injury that can be avoided or reversed by modification of the conditions of reperfusion. ${ }^{1}$ Cardioplegic solutions are widely used to protect the myocardium against ischemic injury. Besides having anti-ischemic effects, volatile anesthetics were recently found to offer specific protective actions against myocardial reperfusion injury. ${ }^{2-4}$ An additional protection against myocardial reperfusion injury was also shown for the inhaled anesthetics enflurane and isoflurane after protecting the heart against the ischemic injury by cardioplegic arrest. ${ }^{5}$ Protective effects of halothane in this preparation depended on the calcium concentration of the cardioplegic solution and were absent with the low calcium containing HTK solution. ${ }^{5}$ Previous studies demonstrated that the new anesthetics sevoflurane and desflurane also offered protection against reperfusion injury and, simultaneously, had smaller myocardial depressant effects than enflurane and halothane, both in vitro and in vivo. ${ }^{6,7}$ Therefore, these anesthetics might be preferable in clinical ischemia-reperfusion situations such as after aortic cross-clamping for coronary artery bypass surgery. No data are available about the actions of these anesthetics on myocardial tissue after cardioplegic arrest. We, therefore, investigated whether sevoflurane or desflurane offered additional protection against reperfusion damage after protecting the heart against the ischemic injury by cardioplegia. To address this question, sevoflurane or desflurane were given during the early reperfusion period after cardioplegic arrest followed by $30 \mathrm{~min}$ of no-flow ischemia in isolated rat hearts. Left ventricular (LV) developed pressure and creatine kinase (CK) release from the coronary venous effluent were determined as variables of myocardial function and cellular injury, respectively.

\section{Methods}

In accordance with the regulations of the German Law on the Protection of Animals and local institutional regulations, male Wistar rats were anesthetised with enflurane and hearts were quickly excised and mounted on a Langendorff perfusion system. Retrograde perfusion via the aortic root was initiated at constant flow with an oxygenated modified Krebs-Henseleit buffer containing (mmol-litre $\left.{ }^{-1}\right): \mathrm{NaCl} 116, \mathrm{KCl} 4.7, \mathrm{MgSO}_{4}$ 1.1, $\mathrm{KH}_{2} \mathrm{PO}_{4} 1.17, \mathrm{NaHCO}_{3} 24.9, \mathrm{CaCl}_{2} 2.52$, glucose 8.3 , and pyruvate 2.0 ; gassed with $\mathrm{O}_{2} 95 \%-\mathrm{CO}_{2} 5 \%$. Flow in the system was controlled by a roller pump (model 7518, Cole-Parmer Instruments, IL, USA). During surgical preparation, hearts were perfused at a flow of $15 \mathrm{ml} \cdot \mathrm{min}^{-1}$. Flow was then reduced to 12 $\mathrm{ml} \cdot \mathrm{min}^{-1}$ and kept constant throughout the perfusion period. The right ventricle was vented via the pulmonary artery with a Teflon catheter $(1.0 \mathrm{~mm}$ od). A latex balloon (\# 4, Hugo Sachs Elektronik, March, Germany) was introduced via the cut mitral valve into the left ventricle for measurement of LV pressure. The balloon was fixed at the tip of a stainless steel cannula (length $5.9 \mathrm{~cm}$ ) which was connected directly to a pressure transducer (Gould P23, Cleveland, OH, USA). Heart rate in control and treatment hearts was maintained constant at 375 beats $\mathrm{min}^{-1}$. After completion of the experimental preparation, the heart was placed in a water-jacketed chamber at $37^{\circ} \mathrm{C}$, filled with humidified, warmed air. During ischemia, the heart chamber was filled with normal saline, gassed with $\mathrm{N}_{2}$.

The $\mathrm{LV}$ pressure and its first derivative, $\mathrm{LV} \mathrm{dP} / \mathrm{dt}$ were monitored continuously on an ink recorder (Gould, Mark 260, Cleveland, OH, USA). At the beginning of each experiment, the latex balloon was filled with Krebs-Henseleit buffer to achieve an enddiastolic LV pressure of $8 \mathrm{mmHg}$. This volume was then held constant for the remainder of the experiment. The LV pressure and coronary perfusion pressure (CPP) were digitized at a sampling rate of $500 \mathrm{~Hz}$ using an analogue-to-digital converter (Data Translation 2801, Marlboro, MA, USA) and then processed further on a personal computer system. The $\mathrm{LV}$ end-diastole was determined as the point when $\mathrm{LV}$ $\mathrm{dP} / \mathrm{dt}$ started its rapid upstroke after crossing the zero line. The LV end-systole was defined as the point of minimum $\mathrm{dP} / \mathrm{dt}$. The $\mathrm{LV}$ peak systolic pressure (LVPSP), LV end-diastolic pressure (LVEDP), LV developed pressure (systolic minus diastolic LV pressure), the time constant of decrease in isovolumic LV pressure $(\tau)$, and peak positive and negative velocity of the change of LV pressure $\left(\mathrm{dP} / \mathrm{dt}_{\max }\right.$ and $\left.\mathrm{dP} / \mathrm{dt}_{\min }\right)$ were obtained from the digitized signals.

Aliquots from the perfusion medium and the coronary venous effluent perfusate were sampled and processed immediately for $\mathrm{PO}_{2}$ measurements (ABL 30, Radiometer, Copenhagen, Denmark). Oxygen consumption $\left(\mathrm{VO}_{2}\right)$ was calculated according to the Fick principle with use of Bunsen's absorption coefficient. The CK release was measured in one-minute samples of the effluent with an "optimised standard method" (CK test, Boehringer, Mannheim, Germany). After each experiment, the wet and dry weight of the heart were measured. Mean wet weight was $1.02 \mathrm{~g}$ (range 0.80$1.22 \mathrm{~g}$ ), and mean dry weight was $0.211 \mathrm{~g}$ (range $0.165-0.325 \mathrm{~g}$ ), similar in all groups. Myocardial oxygen consumption and CK release were expressed per gram of dry tissue. 
TABLE Hemodynamic variables.

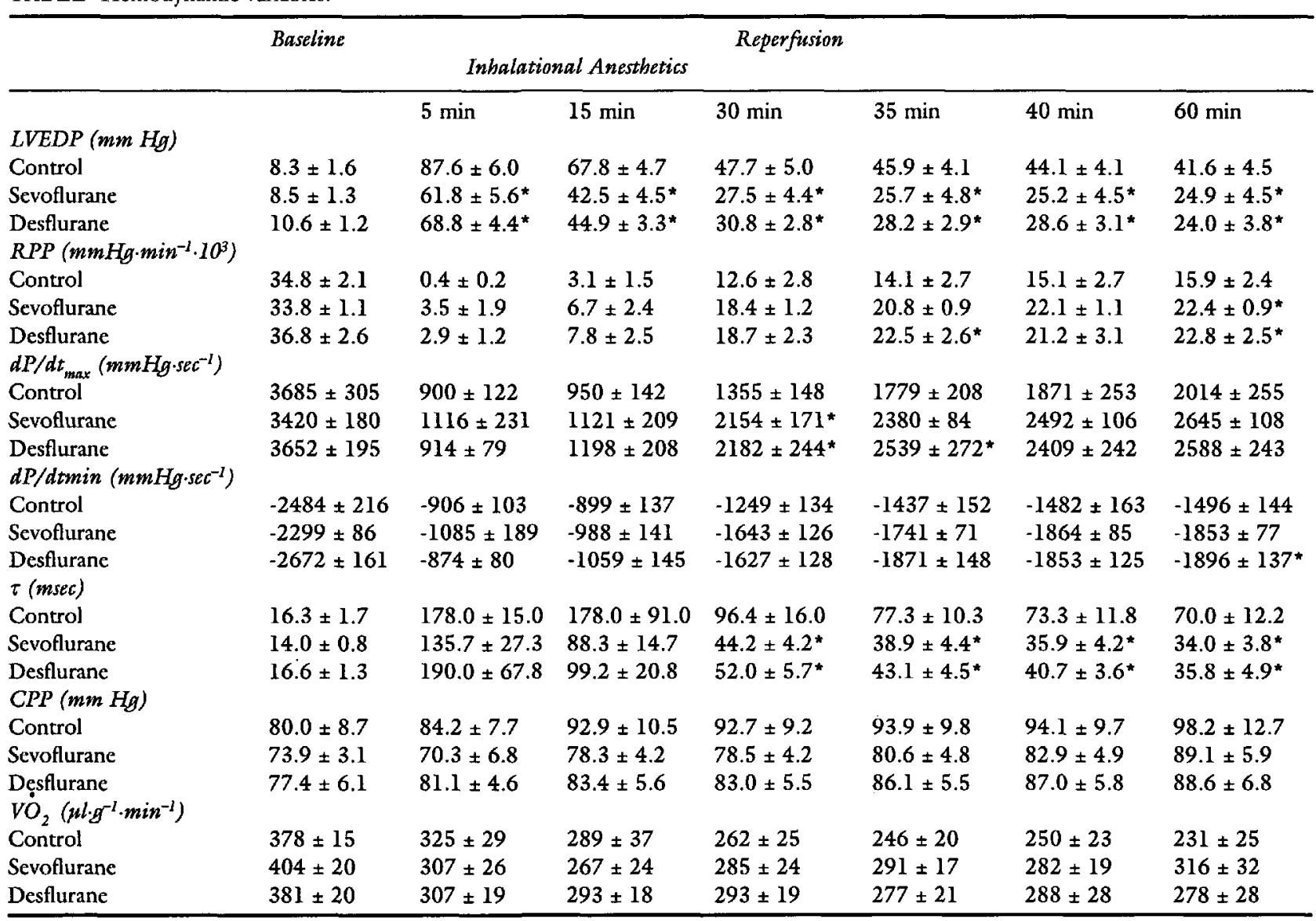

Data are mean \pm SEM. LVEDP $=$ left ventricular end-diastolic pressure; $\mathrm{RPP}=$ rate pressure product; $\mathrm{dP} / \mathrm{dt}_{\max }$ and $\mathrm{dP} / \mathrm{dt}_{\text {min }}=$ peak positive and negative velocity of the change of left ventricular pressure; $\tau=$ time constant of decrease in isovolumic left ventricular pressure; $\mathrm{CPP}=$ coronary perfusion pressure; $\mathrm{VO}_{2}=$ oxygen consumption; ${ }^{*} P<0.05$ vs Control.

After mounting the heart on the Langendorff apparatus, a preparation and stabilisation period of $20 \mathrm{~min}$ was allowed. After obtaining baseline values, the hearts were arrested by infusion of cold HTK (Köhler, Alsbach, Germany) cardioplegic solution for two minutes $\left(7^{\circ} \mathrm{C}, 2 \mathrm{ml} \cdot \mathrm{min}^{-1}\right.$, HTK contains $\left(\mathrm{mmol} \cdot \mathrm{l}^{-1}\right)$ : $\mathrm{NaCl} 15, \mathrm{KCl} 9$, K-ketoglutarate $1, \mathrm{MgCl}_{2} 4$, histidine 180 , histidine- $\mathrm{HCl} 18$, tryptophan 2 , mannitol 30 , $\mathrm{CaCl}_{2} 0.015$, aqua ad injectabilia, $\mathrm{KOH} 2 \mathrm{~N}, \mathrm{pH}=7.2$ at $7^{\circ} \mathrm{C}$, measured $\mathrm{K}^{+}$-concentration $11.15 \mathrm{mmol} \cdot \mathrm{l}^{-1}$, $310 \mathrm{mosmol} \cdot \mathrm{l}^{-1}$ ). The hearts underwent $30 \mathrm{~min}$ noflow ischemia and $60 \mathrm{~min}$ reperfusion with the oxygenated medium. A hollow fibre oxygenator (D705 Midflow, DIDECO, Mirandola, Italy) was integrated into the perfusion system. Sevoflurane $(n=9)$ or desflurane $(n=9)$ was supplied to the perfusion medium during the first $30 \mathrm{~min}$ of reperfusion using a calibrated vaporizer (Vapor 19.3, Devapor, Drägerwerke
Lübeck, Germany) and the hollow fibre oxygenator to achieve a perfusate concentration of inhaled anesthetics corresponding to $1.5 \mathrm{MAC}$ in the rat (sevoflurane, 3.6\%; desflurane, $10.8 \%) .9,10$ Anesthetic concentration in the gas outlet of the oxygenator was determined continuously with a Datex infrared gas analyser (Datex Capnomac Ultima, Division of Instrumentarium Corp., Helsinki, Finland). Only glass or Teflon tubing was in contact with the anesthetic-containing perfusion medium. Nine hearts underwent cardioplegic arrest followed by ischemia and reperfusion without anesthetics and served as controls.

Data are presented as means and standard error of the mean (SEM). Statistical analysis was done by twoway analysis of variance (ANOVA) for time and treatment (experimental group) effects. If an overall statistically significant difference between groups was found, comparison was done for each time point using 


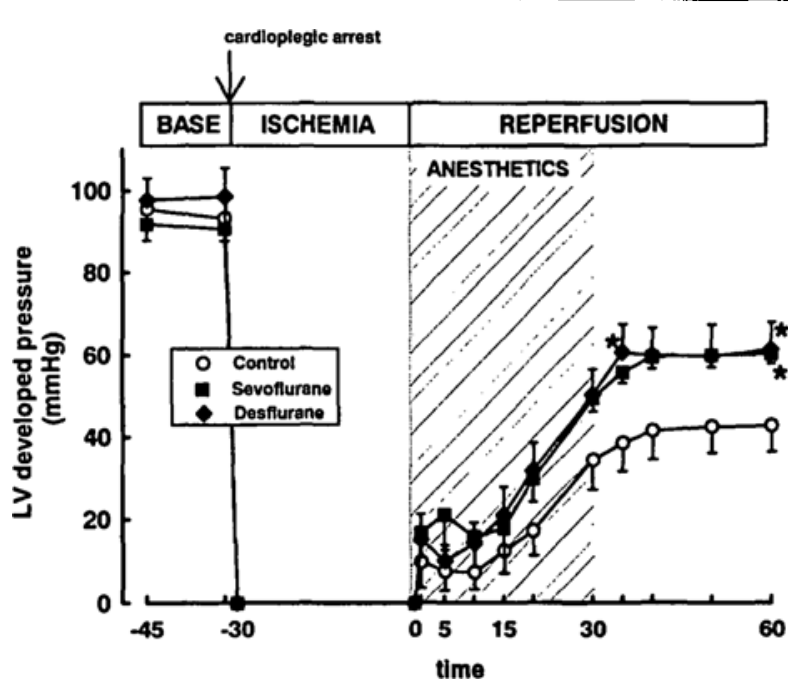

FIGURE 1 The time course of left ventricular (LV) developed pressure during the experiments. Data are mean \pm SEM. *, $P<0.05$ vs control.

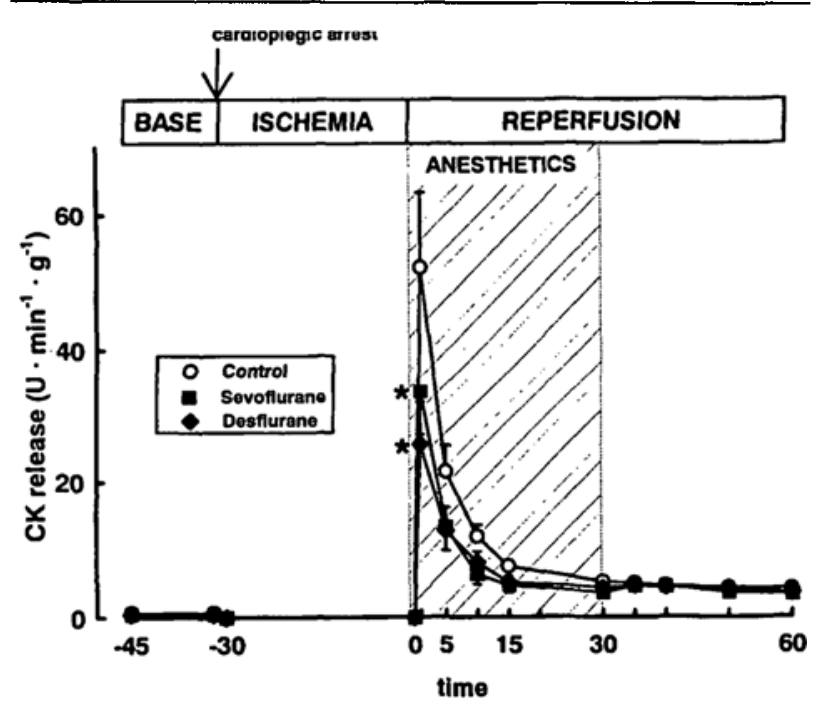

FIGURE 2 The time course of creatine kinase (CK) release during the experiments. Data are mean \pm SEM. ${ }^{*}, P<0.05 v$ s control.

one-way ANOVA followed by Dunnett's test as a post-hoc test. Differences with $P<0.05$ were regarded as significant.

\section{Results}

An increase in LVEDP was observed during the ischemic period (ischemic contracture), reaching max- imal values of $63.6 \pm 5.2 \mathrm{mmHg}$ in controls, $52.7 \pm$ $5.5 \mathrm{mmHg}(P=0.54$ ps control) in sevoflurane and $58.2 \pm 4.8 \mathrm{mmHg}(P=0.83$ vs control) in desflurane treated hearts. With the onset of reperfusion, a reoxygenation induced contracture occurred, resulting in an increase of LVEDP to $87.6 \pm 6.0 \mathrm{mmHg}$ in controls, followed by a slow decrease during the remainder of the experiment to $41.6 \pm 4.5 \mathrm{mmHg}$ at $60 \mathrm{~min}$ of reperfusion. Reoxygenation induced contracture was markedly attenuated by sevoflurane and desflurane and LVEDP was lower during reperfusion in the treatment groups than in control hearts (Table). Discontinuation of sevoflurane or desflurane after 30 min of reperfusion had no effect on LVEDP.

The LV developed pressure during baseline was similar in all groups and decreased to zero with the onset of ischemia (Figure 1). During reperfusion, LV developed pressure recovered to $46 \pm 7 \%$ of baseline in controls. Sevoflurane and desflurane slightly improved LV developed pressure as soon as one minute after the onset of reperfusion. The LV developed pressure recovered to $67 \pm 3 \%$ and $61 \pm 5 \%$ of baseline in sevoflurane and desflurane treated hearts at the end of the reperfusion period, both different from controls (Figure 1). Because of constant heart rate, changes of LV developed pressure were paralleled by changes in rate pressure product (Table). With regard to LV diastolic function, both sevoflurane and desflurane improved recovery of $\tau$ during the reperfusion period (Table), indicating a better relaxation during reperfusion after administration of the inhaled anesthetics. Coronary perfusion pressure slightly increased during myocardial reperfusion, but there were no differences among groups.

No relevant $\mathrm{CK}$ release was observed during baseline perfusion (Figure 2). The peak $\mathrm{CK}$ release occurred after one minute of reperfusion in controls. Inhaled anesthetics reduced this peak CK release from $52 \pm 11 \mathrm{U} \cdot \mathrm{min}^{-1} \cdot \mathrm{g}^{-1}$ (controls) to $34 \pm 7 \mathrm{U} \cdot \mathrm{min}^{-1} \cdot \mathrm{g}^{-1}$ (sevoflurane) and $26 \pm 7 \mathrm{U} \cdot \mathrm{min}^{-1} \cdot \mathrm{g}^{-1}$ (desflurane, $P=0.05$ ). Calculated cumulative $\mathrm{CK}$ release during the first 30 min of reperfusion was $312 \pm 41 \mathrm{U} \cdot \mathrm{g}^{-1}$ in control hearts and was reduced to $195 \pm 40 \mathrm{U} \cdot \mathrm{g}^{-1}$ $(P=0.08)$ and to $206 \pm 37 \mathrm{U} \cdot \mathrm{g}^{-1}(P=0.12)$ in sevoflurane and desflurane treated hearts, respectively.

\section{Discussion}

The main finding of the present study was that the administration of sevoflurane and desflurane during early reperfusion reduced myocardial reperfusion injury after protecting the heart against the ischemic injury by cardioplegic arrest, as demonstrated by an improved functional recovery and a reduced CK release. 
Myocardial reperfusion injury may occur in a variety of clinical settings, for example after periods of cardiac arrest during heart surgery with cardiopulmonary bypass. Cardioplegic arrest is often used to protect the heart against ischemic injury, and previous research has mainly focused on different anti-ischemic effects of different cardioplegic solutions. ${ }^{11,12}$ We used HTK cardioplegic solution according to the clinical protocol in our university hospital. This solution has been previously shown to reduce ischemic injury and to improve recovery of myocardial function compared with hearts not arrested by cardioplegia in an isolated rat heart model. ${ }^{5}$ Besides anti-ischemic effects, ${ }^{13-16}$ volatile anesthetics offer specific actions to mechanisms involved in the pathogenesis of myocardial reperfusion injury in different experimental setups. ${ }^{2-4,6,7}$ In a previous series of experiments the administration of enflurane or isoflurane during early reperfusion offered additional protection against reperfusion injury after protecting the heart against the ischemic injury by cardioplegic arrest with the HTK solution. ${ }^{5}$ Surprisingly, protective effects of halothane solely against cellular injury were observed only when cardioplegia contained a higher calcium concentration. It has also been shown that sevoflurane and desflurane offered protection against reperfusion injury, ${ }^{6,7}$ and these findings are extended by the present study to the reperfusion situation after ischemic protection of the heart by cardioplegic arrest. The protective effect of the new inhalational anesthetics seems to be less than the effects of enflurane and isoflurane. ${ }^{5}$ Most previous studies administered the volatile anesthetics for a short period directly before reperfusion using anoxic wash-in to assure that the protective substances were present at the onset of reperfusion when mitochondrial energy production is reactivated, creating the danger of hypercontracture. ${ }^{17}$ The protocol of the present study (without anoxic wash-in) is closer to the clinical situation but may offer less protection. Therefore, the results cannot be directly compared with the previous studies. The new inhaled anesthetics have been shown to reduce infarct size after regional ischemia in vivo and, simultaneously, only minimally affected hemodynamic variables. ${ }^{7}$ The present results demonstrate that these anesthetics further markedly improved the recovery of systolic as well as of diastolic function after cardioplegic arrest followed by global ischemia.

Only one concentration of anesthetic was used in the present investigation and the findings must be limited to this concentration. Lower concentrations might offer protective actions in this experimental setup. Inhaled anesthetics were given for the first $30 \mathrm{~min}$ of reperfusion. In anoxic reoxygenated rat cardiomyocytes, halothane reduced calcium oscillations at the sarcoplas- mic reticulum and, thereby, prevented cellular hypercontracture. ${ }^{4}$ In this investigation, intracellular calcium homeostasis recovered within five minutes, and after this period administration of halothane could be discontinued without danger of hypercontracture. Therefore, a shorter period of sevoflurane or desflurane administration might be sufficient.

We used the model of the isolated buffer perfused rat heart to investigate direct effects of the anesthetics on myocardial reperfusion injury. This model excludes several effects of sevoflurane and desflurane that may be important in the in pipo situation of ischemia and reperfusion (hemodynamic and humoral side effects, sympathetic nervous system activity, activation of neutrophils). ${ }^{18,19}$ Therefore, clinical studies are necessary to evaluate the potential protective effects of sevoflurane or desflurane in a clinical situation of ischemia and reperfusion, for example after cardioplegic arrest and aortic cross-clamping during coronary artery bypass surgery.

In summary, we found that treatment with 1.5 MAC sevoflurane or desflurane during reperfusion after cardioplegic arrest with HTK solution followed by global ischemia reduced markedly the extent of myocardial reperfusion injury in the isolated buffer perfused rat heart.

\section{Acknowledgment}

The authors thank Mrs. Elke Hauschildt, BTA, for excellent technical assistance.

\section{References}

1 Rosenkranz ER, Buckberg GD. Myocardial protection during surgical coronary reperfusion. J Am Coll Cardiol 1983; 1: 1235-46.

2 Schlack W, Hollmann $M$, Stunneck J, Thämer V. Effect of halothane on myocardial reoxygenation injury in the isolated rat heart. Br J Anaesth 1996; 76: 860-7.

3 Schlack W, Preckel B, Barthel $H$, Obal D, Thämer V. Halothane reduces reperfusion injury after regional ischaemia in the rabbit heart in vivo. $\mathrm{Br} \mathrm{J}$ Anaesth 1997; 79: 88-96.

4 Siegmund B, Schlack W, Ladilov YV, Balser C, Piper $H M$. Halothane protects cardiomyocytes against reoxygenation-induced hypercontracture. Circulation 1997; 96: 4372-9.

5 Preckel B, Schlack W, Thämer V. Enflurane and isoflurane, but not halothane, protect against myocardial reperfusion injury after cardioplegic arrest with HTK solution in the isolated rat heart. Anesth Analg 1998; 87: 1221-7.

6 Schlack W, Preckel B, Stunneck D, Thämer V. Effects of halothane, enflurane, isoflurane, sevoflurane and desflu- 
rane on myocardial reperfusion injury in the isolated rat heart. Br J Anaesth 1998; 81: 913-9.

7 Preckel B, Schlack W, Comfêre T, Obal D, Bartbel H, Thämer $V$. Effects of enflurane, isoflurane, sevoflurane and desflurane on reperfusion injury after regional myocardial ischaemia in the rabbit heart in vivo. $\mathrm{Br} J$ Anaesth 1998; 81: 905-12.

8 Abel FL. Maximal negative $\mathrm{dP} / \mathrm{d} t$ as an indicator of end of systole. Am J Physiol 1981; 240: H676-9.

9 Conzen PF, Vollmar B, Habazettl H, Frink EJ, Peter $K$, Messmer $K$. Systemic and regional hemodynamics of isoflurane and sevoflurane in rats. Anesth Analg 1992; 74: 79-88.

10 Ganjoo P, Farber NE, Schwabe D, Kampine JP, Schmeling WT. Desflurane attenuates the somatosympathetic reflex in rats. Anesth Analg 1996; 83: 55-61.

11 Hearse DJ, Braimbridge $M V$, Jynge $P$. The working heart preparation. In: Hearse DJ, Braimbridge MV, Jynge P (Eds.). Protection of the Ischemic Myocardium: Cardioplegia. New York: Raven Press, 1981: 59-63.

12 Hearse DJ. Cardioplegia: the protection of the myocardium during open heart surgery: a review. J Physiol Paris 1980; 76: 751-68.

13 Buljubasic N, Marijic J, Stowe DF, Kampine JP, Bosnjak $Z J$. Halothane reduces dysrhythmias and improves contractile function after global hypoperfusion in isolated hearts. Anesth Analg 1992; 74: 384-94.

14. Marijic J, Stowe DF, Turner LA, Kampine JP, Bosnjak $Z J$. Differential protective effects of halothane and isoflurane against hypoxic and reoxygenation injury in the isolated guinea pig heart. Anesthesiology 1990; 73 : 976-83.

15 Coetzee A, Skein W, Genade S, Lochner A. Enflurane and isoflurane reduce reperfusion dysfunction in the isolated rat heart. Anesth Analg 1993; 76: 602-8.

16 Mattheussen $M$, Rusy BF, Van Aken H, Flameng W. Recovery of function and adenosine triphosphate metabolism following myocardial ischemia induced in the presence of volatile anesthetics. Anesth Analg 1993; 76: 69-75.

17 Piper HM. Mitochondrial injury in the oxygen-depleted and reoxygenated myocardial cell. In: Piper HM (Ed.). Pathophysiology of Severe Ischemic Injury. Dordrecht: Kluwer Academic, 1990: 91-114.

18 Lynch C III. Differential depression of myocardial contractility by halothane and isoflurane in vitro. Anesthesiology 1986; 64: 620-31.

19 Kowalski C, Zabler S, Becker BF, et al. Halothane, isoflurane, and sevoflurane reduce postischemic adhesion of neutrophils in the coronary system.

Anesthesiology 1997; 86: 188-95. 